\title{
A TARGET COSTING APPROACH TO DEVELOPING AN ONLINE DISTRIBUTION CHANNEL - Case study -
}

Rainer Lueg, Leuphana University, Germany and University of Southern Denmark, Denmark

\author{
dx.doi.org/10.18374/IJBS-20-1.1
}

\begin{abstract}
This case study illustrates how a retail company uses target costing to develop its online sales channel. The case elaborates on a setting where the investment choices into the different components of the online distribution channel appear intuitive and simple. However, a data-driven analysis that relates user preferences and customer requirements to capital expenditure decisions (target costing) mandates another course of action. The case then addresses managerial implications, specifically in the area of the cost of quality.
\end{abstract}

Keywords: Target costing; online distribution channel; customer accounting; cost of quality; teaching notes. 